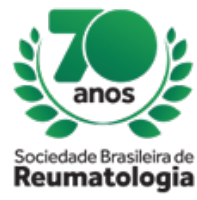

\title{
HIV INFECTION CAUSING NEPHRITIS AND MIMICKING SYSTEMIC LUPUS ERYTHEMATOSUS
}

Igor Tadeu Garcia Ferreira (PUC Campinas, Campinas, SP, Brasil), Claudia Valeria Vierhout (PUC Campinas, Campinas, SP, Brasil), Nadia Regina Bossolan Schincariol (PUC Campinas, Campinas, SP, Brasil), José Alexandre Mendonça (PUC Campinas, Campinas, SP, Brasil), Lucas Eduardo Pedri (PUC Campinas, Campinas, SP, Brasil), André Marun Lyrio (PUC Campinas, Campinas, SP, Brasil), Rubens Bonfiglioli (PUC Campinas, Campinas, SP, Brasil), José Roberto Provenza (PUC Campinas, Campinas, SP, Brasil), Vanessa Ramos Guissa (PUC Campinas, Campinas, SP, Brasil), Flavia Regina Andrade (PUC Campinas, Campinas, SP, Brasil), Marina de Souza Vieira (PUC Campinas, Campinas, SP, Brasil), Fernanda Bertucci Sanches (PUC Campinas, Campinas, SP, Brasil), Thais de Campos Ferreira Pinto (PUC Campinas, Campinas, SP, Brasil)

\section{BACKGROUND}

Nephrotic syndrome is a condition that has several etiologies. This can be secondary to metabolic conditions; infectious diseases such as HIV, hepatitis and post streptococcal glomerulonephritis; secondary to neoplasms; and autoimmune diseases such as systemic lupus erythematosus and small vessel vasculitis. And for the correct diagnosis, it is important to have a good anamnesis, physical examination and extensive laboratory screening and in certain cases renal biopsy.

Among autoimmune diseases, systemic lupus erythematosus is an important cause of renal involvement. Usually, the patient has other signs and symptoms that allow us to differentiate from other causes. It is a diagnosis of exclusion, and concomitantly, extensive research on other causes must be done. In the present case, we demonstrate the case of a patient with HIV infection mimicking SLE clinically and laboratorially.

\section{CASE REPORT}

Patient 21 years old, previously healthy, started with malaise, oliguria of sudden onset, and sought medical attention. He was hypertensive, tachycardic, and had an important anasarca. In the initial screening shows pancytopenia, creatinine of 1.28 and urine I with important hematuria and proteinuria. Evaluated by nephrology, he was diagnosed with nephrotic syndrome and after clinical stabilization, he was discharged with furosemide, losartan and opted for outpatient investigation. As patient had a photosensitivity complaint, a history of weight loss of $15 \mathrm{~kg}$ in the last 3 months, in addition to a history of IgA deficiency without follow-up, he was also referred to the rheumatology outpatient clinic.

In consultation, patient reported that 3 months ago he started with weight loss, photosensitivity, and that it all started after episode of a prolonged tonsillitis. 2 days before the first evaluation he began with oliguria and anasarca. On physical examination, he presented only edema of lower limbs, without hypertension. And brought some lab tests: Pancytopenia, positive ANA, ACNA and direct Coombs, proliferative urine, negative viral serologies, except for HIV, which still awaited the result. Thus, it was decided to refer patients to hospital for better investigation, since the patient presents criteria for SLE.

During hospitalization, viral serologies were requested again, and the patient was HIV positive, and then referred to the care of the infectious team.

\section{CONCLUSION}

As demonstrated in the case report, HIV infection can mimic the manifestations of SLE and collagen diseases. Systemic lupus erythematosus is a disease with a broad clinical spectrum and a diagnosis of 
exclusion, which deserves extensive and careful investigation, with the elimination of other possible causes. 